\title{
Downregulation of the $\beta 1$ adrenergic receptor in the myocardium results in insensitivity to metoprolol and reduces blood pressure in spontaneously hypertensive rats
}

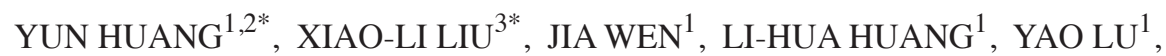 \\ RU-JIA MIAO ${ }^{1}$, XING LIU ${ }^{1}$, YING LI ${ }^{1}$, XIAO-WEI XING ${ }^{1}$ and HONG YUAN ${ }^{1}$ \\ ${ }^{1}$ Center for Clinical Pharmacology, The Third Xiangya Hospital, Central South University, Changsha, Hunan 410013; \\ ${ }^{2}$ Department of Pharmacy, Lihuili Hospital of Ningbo Medical Center, Ningbo, Zhejiang 315000; ${ }^{3}$ Department of Pharmacy, \\ The Second Affiliated Hospital of Hunan University of Traditional Chinese Medicine, Changsha, Hunan 410013, P.R. China
}

Received October 8, 2015; Accepted September 8, 2016

DOI: $10.3892 / \mathrm{mmr} .2016 .6038$

\begin{abstract}
The $\beta 1$-adrenergic receptor (AR) is the primary $\beta$-AR subtype in the heart and is the target of metoprolol (Met), which is commonly used to treat angina and hypertension. Previous studies have revealed a positive correlation between the methylation levels of the adrenoreceptor $\beta 1$ gene $(A d r b 1)$ promoter in the myocardium with the antihypertensive activity of Met in spontaneously hypertensive rats (SHR), which affects $\beta 1-\mathrm{AR}$ expression in $\mathrm{H} 9 \mathrm{C} 2$ cells. The aim of the present study was to investigate the effects of myocardial $\beta 1$-AR downregulation using short-hairpin RNA (shRNA) against Adrbl on the antihypertensive activity of Met in SHR. Recombinant adeno-associated virus type 9 (rAAV9) vectors carrying Adrbl shRNA (rAAV9-Adrb1) or a negative control sequence (rAAV9-NC) were generated and used to infect rat hearts via the pericardial cavity. The results of reverse transcription-quantitative polymerase chain reaction, immunohistochemistry and western blotting analyses demonstrated that cardiac $\beta 1$-AR expression in the rAAV9-Adrb1 group was significantly downregulated when compared with the rAAV9-NC group $(\mathrm{P}<0.001, \mathrm{P}<0.001$ and $\mathrm{P}=0.032$, respectively). In addition, a greater reduction in systolic blood pressure (SBP) was observed in the rAAV9-NC
\end{abstract}

Correspondence to: Professor Hong Yuan or Dr Xiao-Wei Xing, Center for Clinical Pharmacology, The Third Xiangya Hospital, Central South University, 138 Tong-Zi-Po Road, Changsha, Hunan 410013, P.R. China

E-mail: yuanhongxy3@163.com

E-mail: davy2222@163.com

${ }^{*}$ Contributed equally

Key words: $\beta 1$ adrenergic receptor, myocardium, metoprolol, recombinant adeno-associated virus type 9 vector, blood pressure, spontaneously hypertensive rats group compared with the rAAV9-Adrb1 group following Met treatment $(\mathrm{P}=0.035)$. Furthermore, downregulation of myocardial $\beta 1-A R$ was associated with a significant decrease in SBP $(\mathrm{P}<0.001)$. In conclusion, these data suggest that suppression of $\beta 1$-AR expression in the myocardium reduces SBP and sensitivity to Met in SHR.

\section{Introduction}

Hypertension is a multifactorial disease that results from the combined effects of genetic, environmental and behavioral factors (1). Data obtained from the Chinese National Center for Cardiovascular Diseases (Ministry of Health, Beijing, China) indicate that approximately $18.8 \%$ of Chinese adults (aged $\geq 18$ years) were diagnosed with hypertension in 2015 (2). In addition, data obtained from a suburban town of Shanghai demonstrated that the prevalence, awareness, treatment and control rates of hypertension in an elderly Chinese population (aged $\geq 60$ years) from 2006 to 2008 were 59.4, $72.5,65.8$ and $24.4 \%$, respectively (3). In addition, the Global Burden of Disease Study 2010 revealed that blood pressure is one of the leading risk factors for the global disease burden (4). In Africa, hypertension is the leading cause of heart failure (5). Globally, hypertension is responsible for $>50 \%$ of mortalities due to stroke (5). Therefore, studies that aim to identify effective treatments for hypertension are important for the prevention of heart failure and stroke. $\beta$-blockers are commonly prescribed for the treatment of cardiovascular diseases, such as hypertension. The selective $\beta$-blocker, known as metoprolol (Met), is considered to be an effective therapy as it has been demonstrated to reduce mortality rates and adverse cardiac events among patients with coronary artery disease, heart failure and hypertension $(6,7)$. However, only $\sim 50 \%$ of patients with hypertension respond to $\beta$-blocker treatment (8).

In previous studies, polymorphisms in the adrenoreceptor $\beta 1$ gene (Adrbl) and cytochrome P4502D6 (CYP2D6) genes are reportedly involved in the inter-individual differences in the response to Met treatment $(9,10)$. Approximately $70-80 \%$ of Met is known to be metabolized by CYP2D6, and CYP2D6 
polymorphisms have been demonstrated to affect the rate of Met metabolism (11). Previous studies investigating Adrbl polymorphisms have focused primarily on the Ser49Gly and Arg389Gly polymorphisms. For instance, Wu et al (12) demonstrated that Chinese patients with essential hypertension that were homozygous for a mutant Adrbl genotype (Arg389), exhibited an increased sensitivity to Met treatment. By contrast, an additional study demonstrated that subjects with the same CYP2D6 and Adrbl genotypes exhibited varying responses to Met, which suggests that additional mechanisms responsible for the inter-individual differences in Met responses may exist (13).

The $\beta 1$ adrenergic receptor ( $\beta 1-\mathrm{AR})$ is the primary $\beta$-AR subtype in the heart and is the target of Met (14). A previous study conducted by our group demonstrated a correlation between reduced Adrbl promoter methylation levels in the myocardium and enhanced Met-mediated antihypertensive activity in spontaneously hypertensive rats (SHR), and increased $\beta 1-\mathrm{AR}$ expression in H9C2 cells (15). Thus, the authors hypothesized that the expression levels of myocardial $\beta 1$-AR may affect the antihypertensive activity of Met, and may be responsible for the observed inter-individual variations in the response to Met treatment in patients with hypertension (16).

In the present study, a recombinant adeno-associated virus type 9 (rAAV9) vector containing a short-hairpin RNA (shRNA) sequence against Adrbl, was used to inhibit $\beta 1-A R$ expression in the myocardium, in order to investigate the effects of reduced cardiac $\beta 1-\mathrm{AR}$ expression on the antihypertensive efficacy of Met in SHR. The data suggest a novel mechanism underlying the observed inter-individual differences in the response to Met treatment.

\section{Materials and methods}

Plasmids and cell culture. Plasmids containing shRNA sequences against rat $\beta 1$-AR or non-targeting controls were purchased from Changsha Yingrun Biotechnology Co., Ltd. (Changsha, China). Adeno-associated virus (AAV) packaging mixtures were obtained from the Institute of Biomedicine and Biotechnology (Shenzhen Institutes of Advanced Technology, Chinese Academy of Sciences, Shenzhen, China). The HEK293 human embryonic kidney cell line was obtained from Vector Gene Technology Company Ltd. (Beijing, China) and cultured in Dulbecco's modified Eagle's medium (DMEM) containing $10 \%$ fetal bovine serum (FBS).

Preparation of rAAV9 vectors. rAAV9 vectors containing Adrbl shRNA (rAAV9-Adrb1-shRNA-ZsGreen) or negative control (rAAV9-NC-ZsGreen) shRNA sequences were prepared in HEK293 cells as described previously $(17,18)$. Briefly, polyethylenimine (1 $\mu \mathrm{g} / \mu \mathrm{l}$; Helixgen, Co., Ltd., Guangzhou, China) was added to the AAV Packaging Plasmid, target plasmid and Ad Helper $(1.5 \mathrm{ml} ; 20 \mu \mathrm{g}$ : $10 \mu \mathrm{g}$ : $30 \mu \mathrm{g}$ ), mixed and incubated at room temperature for $15 \mathrm{~min}$ to generate the transfection mixture. The transfection mixture was then added to HEK293 cells $\left(9 \times 10^{6}\right)$ and incubated for 8-12 h. The medium was replaced with fresh 10\% FBS-DMEM and incubated for $72 \mathrm{~h}$, before cells and rAAV9 virus particles were harvested. The mixture was purified using chloroform, precipitated using polyethylene glycol/ $\mathrm{NaCl}$ and extracted with chloroform as described previously (19). The purity of rAAV-ZsGreen was evaluated by gel electrophoresis using $12 \%$ SDS-PAGE gels. To achieve this, the viral stock solution was mixed with loading buffer (2X; Thermo Fisher Scientific, Inc., Waltham, MA, USA) and incubated in boiling water for $10 \mathrm{~min}$. Samples $(15 \mu \mathrm{l})$ were then loaded and run at $20 \mathrm{~mA}$ for $2.5 \mathrm{~h}$. The gel was stained with Coomassie Brilliant Blue R250 (Amresco, LLC, Solon, OH, USA) for $1 \mathrm{~h}$ and destained, until clear bands with a low background were evident. The viral titer, expressed as viral genomes (v.g.)/ml, was determined using dot blot hybridization as described previously (20). The efficiency of infection was validated by infecting HEK293 cells. Briefly, $10 \mu 1$ purified virus was added to HEK293 cells $\left(5 \times 10^{5}\right)$ and incubated for $48 \mathrm{~h}$ at $37^{\circ} \mathrm{C}$. Fluorescence signals were then visualized using an Olympus IX71 fluorescence microscope (Olympus Corporation, Tokyo, Japan).

Experimental animals. A total of 36 male SHR (age, 20 weeks; weight, $300 \mathrm{~g}$ ) were purchased from Vital River Laboratory Animal Technology Co., Ltd. (Beijing, China). Rats were acclimated to laboratory conditions for one week before experimental procedures were performed according to the Guidelines for the Care and Use of Laboratory Animals (National Institutes of Health, publication 86-23, revised 1986) and the animal regulations of the Department of Science and Technology of Hunan Province (Changsha, China). Rats were maintained at the Animal Experiment Center of Central South University (Changsha, China), and housed in individual cages at $22 \pm 2^{\circ} \mathrm{C}$ and $55 \pm 5 \%$ humidity with 12 -h environmental light/dark cycles with free access to standard laboratory chow and tap water during the experimental period.

The rats were randomly divided into the following three groups of 12: i) Sham-operated; ii) rAAV9-NC; and iii) rAAV9-Adrb1. Rats in the rAAV9-NC and rAAV9-Adrb1 groups were injected with a single dose of $1 \times 10^{12} \mathrm{v.g} . / \mathrm{kg}$ rAAV9-NC or rAAV9-Adrb1 into the myocardium via the pericardial cavity using the methods described previously $(21,22)$. Briefly, SHR were anesthetized with $10 \%$ chloral hydrate $(300 \mathrm{mg} / \mathrm{kg})$, and each rat was placed in a supine position before connecting to an endotracheal tube. The tidal volume was set at $10 \mathrm{ml}$, and the ventilator rate was set at 75 -breaths $/ \mathrm{min}$. A 2-cm skin incision was made over the fourth intercostal space, which separated the subcutaneous tissue and the underlying muscle, thereby permitting entrance to the thorax via the fourth intercostal space. The pericardial cavity was injected with $200 \mu 1$ vector using an insulin syringe. The muscle and the skin were closed following injection. The rats received penicillin for three days via intramuscular injections to prevent infection. $50 \%$ of rats in each group received saline $(10 \mathrm{ml} / \mathrm{kg})$, while the remaining rats received Met $(50 \mathrm{mg} / \mathrm{kg} /$ day $)$ via oral gavage twice a day for 4 weeks. The systolic blood pressure (SBP) of the rats was monitored weekly using a tail blood pressure meter. The rats were sacrificed by intraperitoneal injection of $10 \%$ chloral hydrate $(300 \mathrm{mg} / \mathrm{kg}$; Hunan Xiangya Medicine Co., Ltd., Changsha, China) 4 weeks after the initial treatment.

Transfection efficiency of rAVV9 vectors. The transfection efficiency of rAAV9-shRNA-Adrb1-ZsGreen was determined at 4 weeks following rAAV9 injection, at which point the 
hearts were harvested and myocardial tissue $(150 \mathrm{mg})$ was collected. The heart tissue was washed with ice-cold saline, immersed in $4 \%$ paraformaldehyde overnight, dehydrated in consecutive $15 \%$ and $30 \%$ sucrose solutions and dried with filter paper. Tissue sections were then embedded in paraffin at room temperature, and divided into $10-\mu \mathrm{m}$ frozen sections. Cell nuclei were visualized by staining tissue sections with DAPI, and blue and green fluorescence signals were visualized using an Olympus IX-71 fluorescence microscope (Olympus Corporation).

Evaluation of $\beta 1-A R$ mRNA expression using reverse transcription-quantitative polymerase chain reaction $(R T-q P C R)$. Following excision of the heart from rats in each experimental group, a portion of the heart was used to measure $\beta 1$-AR mRNA expression levels by RT-qPCR. Briefly, total RNA was extracted from each heart using the RNA-Solv Reagent (Omega Bio-Tek, Inc., Norcross, GA, USA) according to the manufacturer's instructions. Total RNA $(1 \mu \mathrm{g})$ was then reverse transcribed to generate cDNA using the to Revert Aid First Strand cDNA Synthesis kit (Thermo Fisher Scientific, Inc.). qPCR reaction mixtures (10 $\mu \mathrm{l})$ consisted of $5 \mu \mathrm{l} \mathrm{SYBR}$ Green (Omega Bio-Tek, Inc.), $0.8 \mu \mathrm{l} \mathrm{cDNA}$ and $0.2 \mu \mathrm{l}$ each primer. The following primers were used: Adrb1 (Rattus norvegicus) forward, 5'-CGCTGC CCTTTCGCTACCAG-3' and reverse, 5'-CCGCCACCAGTG CTGAGGAT-3'; $\beta$-actin forward, 5'-CGTAAAGACCTCTAT GCCAA-3', and reverse, 5'-GGTGTAAAACGCAGCTCA GT-3' (Nanjing GenScript Biotechnology Co., Ltd., Nanjing, China). The thermal cycling parameters were as follows: $95^{\circ} \mathrm{C}$ for $15 \mathrm{~min}$, followed by 40 cycles of $95^{\circ} \mathrm{C}$ for $15 \mathrm{sec}$, $60^{\circ} \mathrm{C}$ for $30 \mathrm{sec}$ and $72^{\circ} \mathrm{C}$ for $30 \mathrm{sec}$. Target gene expression levels were quantified relative to $\beta$-actin expression using the $2^{-\Delta \Delta \mathrm{Cq}}$ method (23).

Evaluation of $\beta 1-A R$ protein expression by western blot analysis. Heart tissue $(50 \mathrm{mg})$ was lysed in lysis buffer consisting of phenylmethylsulfonyl fluoride and radioimmunoprecipitation assay buffer (1:100; Applygen Technologies Inc., Beijing, China) and centrifuged at $16.2 \times \mathrm{g}$ for $40 \mathrm{~min}$ at $4^{\circ} \mathrm{C}$, before total protein was quantified using a bicinchoninic acid assay kit (Beijing Kawin Biotech Co., Ltd., Beijing, China). For the western blot analysis, $80 \mu \mathrm{l}$ sample ( $50 \mu \mathrm{g}$ protein) was separated by $8 \%$ SDS-PAGE, and proteins were transferred to polyvinylidene difluoride membranes. After blocking with $5 \%$ non-fat milk in phosphate-buffered saline for $5 \mathrm{~h}$ at room temperature, membranes were incubated with polyclonal rabbit antibodies against Adrb1 (dilution, 1:1,000; cat. no. ab3442; Abcam, Cambridge, MA, USA) or GAPDH (dilution, 1:3,000; cat. no. 10494-1-AP, ProteinTech Group, Inc., Chicago, IL, USA) overnight at $4^{\circ} \mathrm{C}$. Membranes were then incubated with horseradish peroxidase-conjugated goat anti-rabbit secondary antibody (dilution, 1:8,000; cat. no. 10285-1-AP; ProteinTech Group, Inc.) for $1 \mathrm{~h}$ at room temperature. Chemiluminescence was detected using the ECL Western Blotting Substrate kit (Abnova Corporation, Taipei, Taiwan), and the relative intensity of the bands of interest were analyzed using Image J image analysis software (version, 1.44p; National Institutes of Health, Bethesda, MD, USA). The expression of $\beta 1$-AR was calculated relative to GAPDH.
Evaluation of $\beta 1-A R$ protein expression by immunohistochemical analysis. Following excision of rat hearts, they were fixed in $4 \%$ paraformaldehyde and embedded in paraffin. Heart tissue sections were blocked using $5 \mathrm{ml}$ horse serum (ZSGB-Bio, Beijing, China) at room temperature for $1 \mathrm{~h} . \beta 1-\mathrm{AR}$ expression was detected by staining with a polyclonal rabbit anti- $\beta 1-A R$ antibody (dilution, 1:100; cat. no. 10285-1-AP; ProteinTech Group Inc.) overnight at $4^{\circ} \mathrm{C}$, followed by staining with hematoxylin. The integrated optical density of the positive expression area of the myocardial tissue sections was calculated using Image-Pro Plus software (version, 6.0; Media Cybernetics, Inc., Rockville, MD, USA).

Measurement of heart rate and SBP. The heart rate and SBP in conscious, resting rats was measured weekly using a tail-cuff method with an electrosphygmomanometer attached to a computerized recorder (Shanghai Alcott Biotech Co., Ltd., Shanghai, China) from 14:30-17:30 p.m. by the same investigator (Miss Xiao-Li Liu, The Second Affiliated Hospital of Hunan University of Traditional Chinese Medicine, Changsha, China). Each rat was held in a silent, dark and sizeable cylinder. Blood pressure measurements were performed in a blind manner, and the mean of three repeated measurements for each rat during each session was recorded.

Statistical analysis. Data are expressed as mean \pm standard deviation. Levene's test was used to assess the equality of variances. One-way analysis of variance with the least significant difference test was used to compare the differences among the experimental and control groups. Data analyses were performed using the SPSS software program (version, 17.0; SPSS, Inc., Chicago, IL, USA). $\mathrm{P}<0.05$ was considered to indicate a statistically significant difference.

\section{Results}

Validating the purity and titer of rAAV9 vectors and the transfection efficiency in HEK293 cells. The purity of rAVV9-shRNA-Adrb1-ZsGreen plasmid vectors was assessed using SDS-PAGE followed by Coomassie brilliant blue (CBB) staining. Three characteristic protein bands for viral protein (VP) 1, VP2 and VP3, with molecular weights of 87, 73 and $62 \mathrm{KDa}$, respectively, were observed, indicating the purity of the rAAV9 vector (Fig. 1A). Dot blot results demonstrated that the vector titer was $1.5 \times 10^{12} \mathrm{~V} . \mathrm{g} . / \mathrm{ml}$ (Fig. 1B). Transfection efficiency was assessed by infecting HEK293 cells and visualizing green fluorescence signals with a fluorescence microscope. As shown in Fig. 1C, approximately $90 \%$ of the cells exhibited green fluorescence.

Determination of rAAV9-Adrb1-shRNA-ZsGreen expression in vivo. In order to investigate the efficiency of rAAV9-Adrb1-shRNA-ZsGreen delivery in vivo, the expression of ZsGreen in heart tissue sections of rats from the sham-operated, rAAV9-Adrb1 and rAAV9-NC groups at 4 weeks following injection of rAAV9-Adrb1-shRNA-ZsGreen and rAAV9-NC-ZsGreen vectors into the myocardium was examined by fluorescence microscopy. As shown in Fig. 2B and $\mathrm{C}$, green fluorescence was observed in heart tissues of rAAV9-NC and rAAV9-Adrb1 groups. By contrast, no 

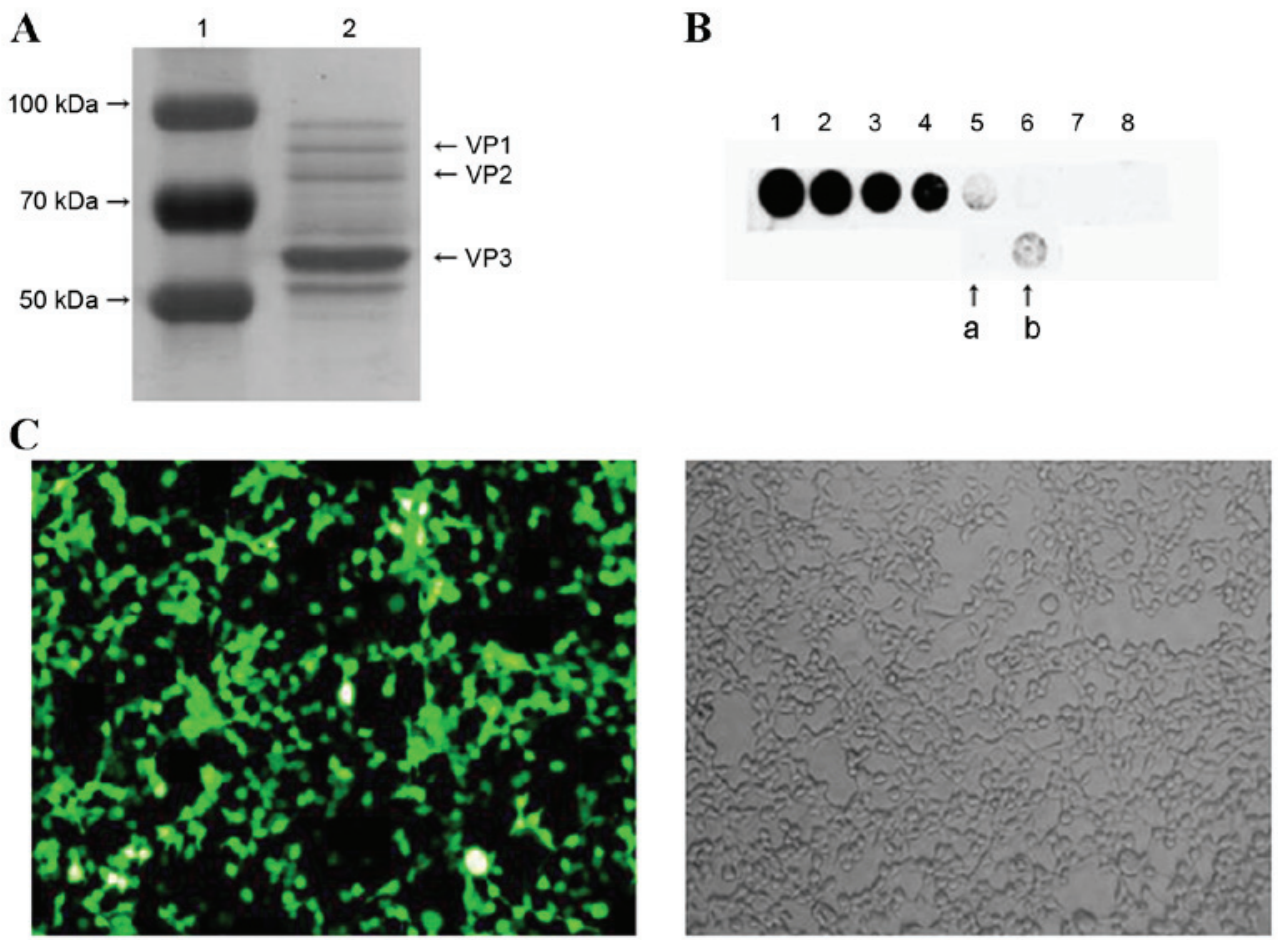

Figure 1.The purity, titer and transfection efficiency of rAAV9-shRNA-Adrb1-ZsGreen vectors in HEK293 cells. (A) The purity of rAAV9-shRNA-Adrb1-ZsGreen vectors as determined by SDS-PAGE followed by Coomassie Brilliant Blue staining. The left lane indicates the protein maker (1), and the right lane indicates the purified vector sample (2). (B) The titer of the purified vectors. Spots $1-8$ indicate $50,25,12.5,6.25,3.125,1.56,0.78$, and $0.39 \times 10^{9} \mathrm{v}$.g./ml purified vector, respectively ( $\mathrm{a}, 2$-fold dilution of purified vectors; b, purified vectors). (C) Fluorescence (left) and light (right) microscope images of the transfection efficiency of rAAV9-shRNA-Adrb1-ZsGreen vectors in HEK293 cells (magnification, x200). rAAV9, recombinant adeno-associated virus type 9 vector; shRNA, short-hairpin RNA; Adrb1, adrenergic receptor $\beta 1$; v.g., viral genomes.

ZsGreen expression was detected in the heart tissues from the sham group (Fig. 2A).

Inhibitory effects of rAAV9-Adrb1-shRNA-ZsGreen on $\beta 1-A R$ expression. In order to assess the inhibitory effects of the injection of rAAV9-Adrb1-shRNA-ZsGreen vectors on $\beta 1$-AR expression in the myocardium, the $\beta 1-\mathrm{AR}$ mRNA expression levels in all experimental groups were examined. Compared with the rAAV9-NC group, cardiomyocytes in the rAAV9-Adrb1 group exhibited a significant decrease in $\beta 1$-AR mRNA expression $(0.42 \pm 0.06$ vs. $1.3 \pm 0.08 ; \mathrm{P}<0.001)$, whereas no significant difference in $\beta 1-A R$ mRNA expression was observed between the sham and rAAV9-NC groups $(1.3 \pm 0.08$ vs. $1.3 \pm 0.06$; $\mathrm{P}>0.05$; Fig. $3 \mathrm{~A}$ ). Immunohistochemical and western blot analyses revealed that cardiomyocytes in the rAAV9-Adrb1 group displayed a significant reduction in $\beta 1$-AR protein expression levels when compared with the rAAV9-NC group (immunohistochemistry, $50.02 \pm 4.4$ vs. $80.05 \pm 3.7, \mathrm{P}<0.001$; western blot, $0.52 \pm 0.12$ vs. $0.83 \pm 0.17$, $\mathrm{P}=0.032$; Fig. 3B-E). Western blot analysis demonstrated no significant difference between $\beta 1-\mathrm{AR}$ protein expression levels between the rAAV9-NC and sham groups $(80.05 \pm 3.7$ vs. $79.30 \pm 2.8 ; \mathrm{P}>0.05$; Fig. 3D and E). These data indicated that 31 -AR expression in the myocardium of SHR was downregulated upon infection with rAAV9-Adrb1-shRNA-ZsGreen but not rAAV9-NC.

Downregulating $\beta 1-A R$ expression in the myocardium results decreased sensitivity to Met. In order to investigate the effects of $\beta 1$-AR downregulation on the response to Met treatment in SHR, the SBP of rats in the sham, rAAV9-NC and rAAV9-Adrb1 groups was examined using a tail blood pressure meter. As shown in Fig. 4, no significant difference in blood pressure was observed among all three experimental groups prior to Met treatment $(\mathrm{P}>0.05)$. Following 4 weeks of Met treatment, a decrease in SBP was observed in all experimental groups (Fig. 4). In addition, a significantly greater reduction in SBP was observed in the sham and rAAV9-NC groups when compared with the rAAV9-Adrb1 group $(\triangle \mathrm{SBP}$, $22.84 \pm 1.7,28.78 \pm 2.7$ and $30.16 \pm 5.7 \mathrm{mmHg}$ for rAAV9-Adrb1, rAAV9-NC and sham groups, respectively; $\mathrm{P}=0.035$; Fig. 4). As shown in Table I, no significant differences in heart rate among the three experimental groups was observed before or after 4 weeks of Met treatment $(\mathrm{P}>0.05)$. However, the heart rate of rats in all groups significantly decreased following 4 weeks of Met treatment $(\mathrm{P}<0.001$; Table I).

Downregulation of $\beta 1-A R$ in the myocardium reduces blood pressure. In addition to the assessment of Met treatment responses, the authors observed an unexpected phenomenon regarding the effects of cardiac $\beta 1-\mathrm{AR}$ downregulation on blood pressure in SHR. As shown in Fig. 5, SBP of SHR in the rAAV9-Adrb1 group was significantly lower than that of the rAAV9-NC group at 4 weeks following injection (178.1 \pm 6.3 vs. $199.4 \pm 3.1 \mathrm{mmHg} ; \mathrm{P}<0.001)$. By contrast, no significant difference in SBP was observed between the rAAV9-NC and sham groups (199.4 \pm 3.1 vs. $198.3 \pm 4.5 \mathrm{mmHg}$; P $>0.05$; Fig. 5). As shown in Table II, no significant differences in heart rate 

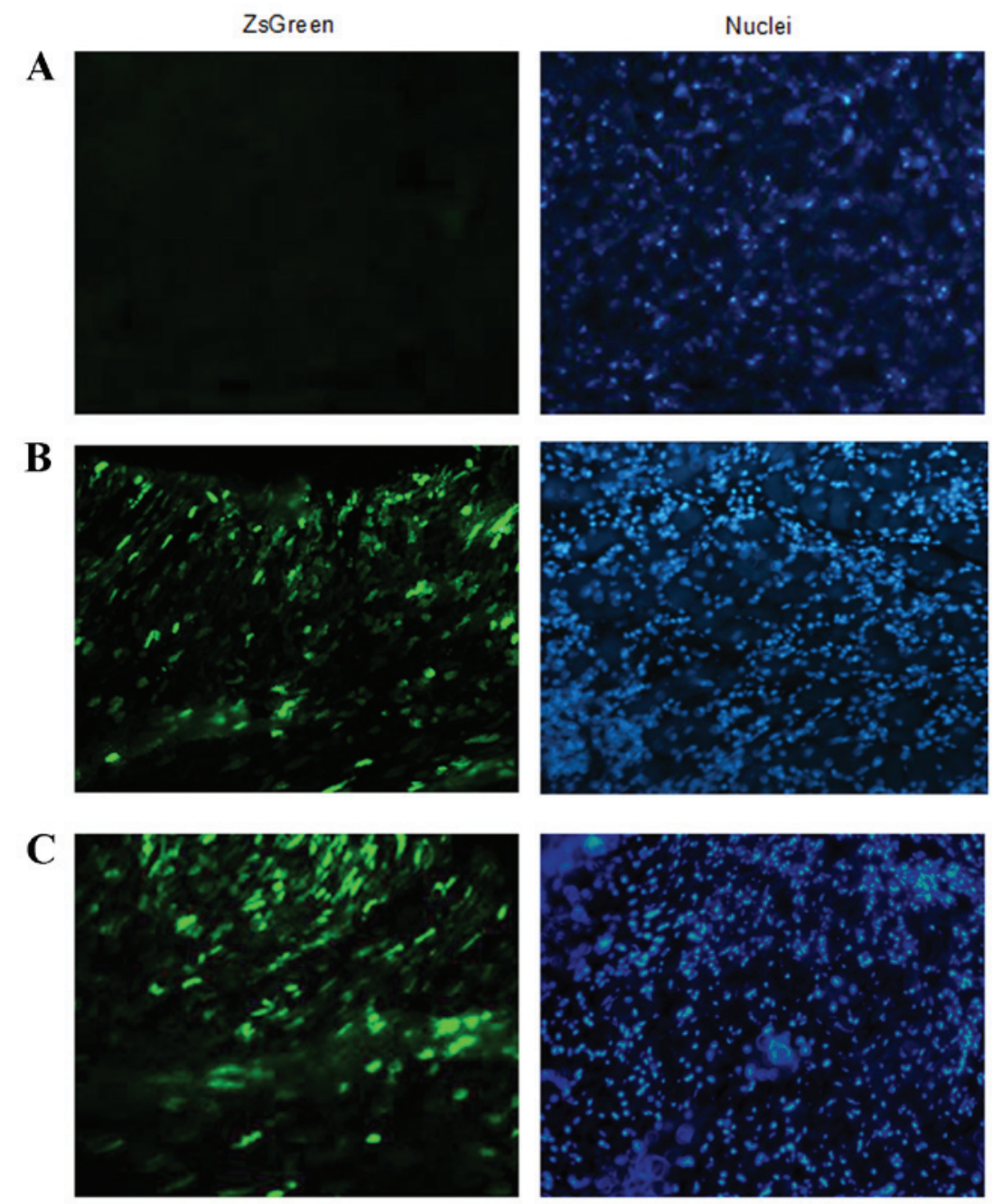

Figure 2. Determination of the efficiency of viral vector delivery in vivo. Fluorescence microscope images (magnification, $\mathrm{x} 200$ ) of ZsGreen expression (left panel) and DAPI staining (right panel) in frozen heart tissues sections derived from rats in the (A) sham-operated (B) rAAV9-NC and (C) rAAV9-Adrb1 groups at 4 weeks following injection with saline, rAAV9-NC-ZsGreen and rAAV9-shRNA-Adrb1-ZsGreen vectors, respectively. rAAV9, recombinant adeno-associated virus type 9 vector; NC, negative control; Adrb1, adrenergic receptor $\beta 1$; shRN, short-hairpin RNA.

of SHR among all treatment groups were observed at 0 or 4 weeks following injection of saline or the rAAV9 vectors $(\mathrm{P}>0.05)$. In addition, no significant difference in the SBP of SHR in the rAAV9-Adrb1 group was observed following treatment with Met or saline at 4 weeks following injection of rAAV9-shRNA-Adrb1-ZsGreen vectors (174.8 \pm 3.9 vs. 178.1 $\pm 6.3 \mathrm{mmHg}$; P>0.05; Fig. 6).

\section{Discussion}

Met is commonly prescribed for the treatment of hypertension. Although its efficacy is extremely variable among patients, the presence of $C Y P 2 D 6$ and Adrbl polymorphisms only provide a partial explanation for this variability (10-12). A previous study investigating Adrbl promoter methylation suggested that the level of Adrbl promoter methylation influences the efficacy of Met via the regulation of $\beta 1-A R$ expression (14). In addition, $\beta 1-\mathrm{AR}$ is the target of Met and its expression has been demonstrated to vary among individuals $(23,24)$. Therefore, the authors of the present study hypothesized that the expression of myocardial $\beta 1$-AR may present a novel mechanism underlying the inter-individual differences in response to Met treatment (15). In order to test this notion, the effect of downregulated cardiac $\beta 1$-AR expression in the response to Met treatment in SHR was investigated in the present study. The results indicated that SHR injected with rAAV9-Adrb1 vectors into the myocardium, exhibited a lower reduction in SBP following Met treatment when compared with negative controls. Naya et al (24) demonstrated that patients with idiopathic dilated cardiomyopathy and decreased myocardial $\beta$-AR expression exhibited a greater sensitivity to the antiadrenergic drug carvedilol in clinical trails. Together, these findings suggest that alterations in myocardial $\beta$-AR expression levels are associated with differential responses to $\beta$-blockers.

A number of factors, including age, drugs and comorbidities are known to influence $\beta 1$-AR expression $(25,26)$. Oliver et al (27) revealed that $\beta 1$-AR expression levels were increased in the circulating lymphocytes of hypertensive patients. Lymphocytes are considered to be a practical surrogate for myocardial or vascular cells. Patients with heart failure exhibit a downregulation and desensitization of $\beta 1-\mathrm{AR}$, which 
A

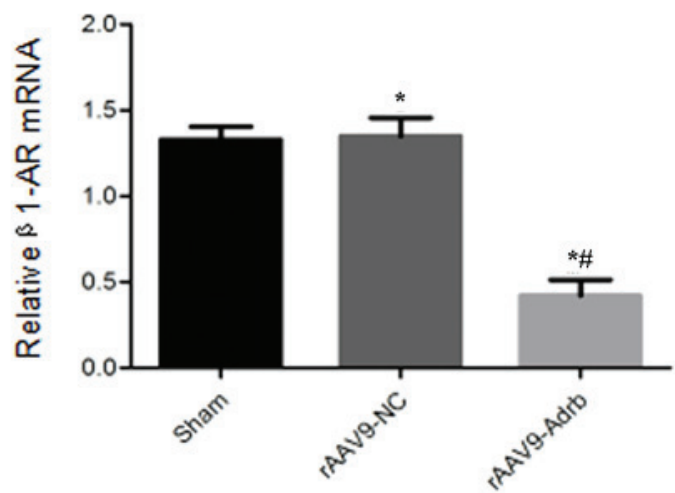

B

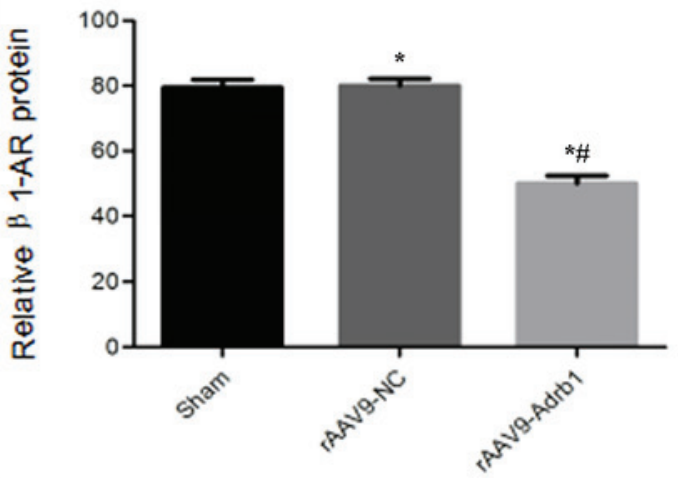

C

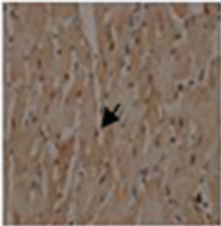

Sham

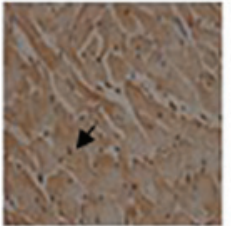

rAAV-NC

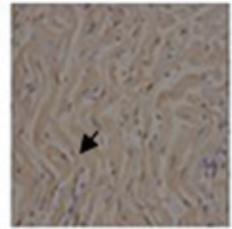

rAAV-Adrb1

D

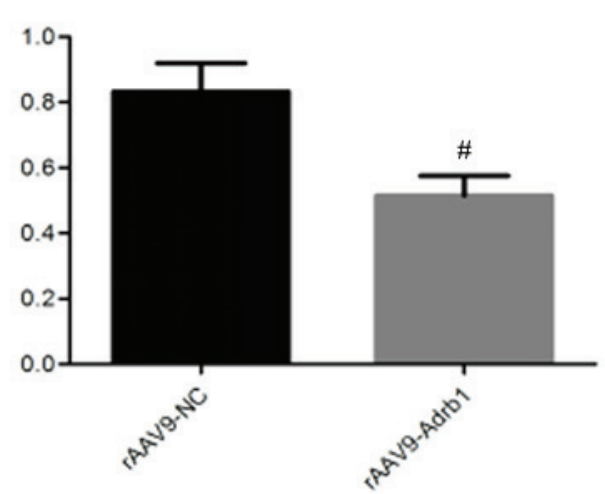

$\mathbf{E}$

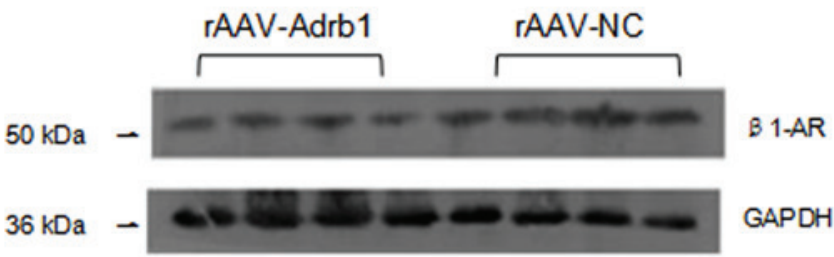

Figure 3. $\beta 1-A R$ mRNA and protein expression levels in the myocardium of SHR from sham, rAAV9-NC and rAAV9-Adrb1 groups at 4 weeks following injection with saline, rAAV9-NC-ZsGreen or rAAV9-shRNA-Adrb1-ZsGreen vectors, respectively. (A) 31 -AR mRNA levels as determined by RT-qPCR. (B) The integrated optical density of $\beta 1$-AR protein levels as determined by immunohistochemical analysis. (C) Representative microscope images (magnification, $\mathrm{x} 400$ ) of $\beta 1$-AR protein levels as determined by immunohistochemical analysis. The black arrows indicate positive protein particles. (D) Relative $\beta 1-A R$ protein levels as determined by western blot analysis. (E) Representative western blot image of $\beta 1$-AR protein levels. GAPDH was used as a loading control. "P<0.05 vs. sham group; ${ }^{~} \mathrm{P}<0.05$ vs. rAAV9-NC group. $\beta 1$-AR, $\beta 1$-adrenergic receptor; SHR, spontaneously hypertensive rats; rAAV9, recombinant adeno-associated virus type 9 vector; NC, negative control; Adrb1, adrenergic receptor $\beta 1$; shRNA, short-hairpin RNA; RT-qPCR, reverse transcription-quantitative polymerase chain reaction.

leads to a markedly diminished $\beta 1$-AR-mediated contractile response (28). In this way, $\beta 1$-AR expression is altered under different physiological conditions, and may potentially be used as a marker of response to different treatments. Therefore, if the hypothesis presented by the authors (15) is accepted by future clinical trials, $\beta 1$-AR expression may be considered as a potential biomarker when establishing a quantitative pharmacological model of patient response to Met for individual therapy.

In addition to the original study objective, the results of the present study demonstrated an unexpected effect of suppressed B1-AR expression on blood pressure in SHR. shRNA-mediated reduction of cardiac $\beta 1-\mathrm{AR}$ expression was associated with a significant decrease in SBP of SHR when compared with negative and sham-treated controls. In addition, this effect on SBP was comparable to Met-treated rAAV9-Adrb1 rats. Several studies have demonstrated that $\beta 1$-AR expression serves a role in the development of cardiovascular diseases, such as hypertension (29-31). The intravenous injection of $\beta 1-A R$ antisense-oligodeoxy nucleotides delivered in cationic liposomes in an animal model of hypertension, demonstrated a significant reduction in cardiac $\beta 1$-AR density of $~ 30-50 \%$ for 18 days, and a reduction in the blood pressure of SHR for 20 days, with a maximum decrease of $38 \mathrm{mmHg}$ (30). Arnold et al (29) developed a small interfering RNA targeted to $\beta 1$-AR that significantly reduced $\beta 1$-AR mRNA levels to $33.3 \%$ of control levels, and lowered diastolic blood pressure in SHR by a maximum of $30 \mathrm{mmHg}$ for $>12$ days. Using 
Table I. Effect of Met on the heart rate of SHR following downregulation of cardiac $\beta 1$-AR expression.

\begin{tabular}{lccc}
\hline & & $\begin{array}{c}\text { Heart rate } \\
\text { prior to Met } \\
\text { intervention } \\
\text { Group }\end{array}$ & $\begin{array}{c}\text { Heart rate } \\
\text { following Met } \\
\text { intervention } \\
\text { samples }\end{array}$ \\
\hline Sham+Met & 4 & $461.7 \pm 3.7$ & $435.7 \pm 3.3^{\mathrm{a}}$ \\
rAAV9-NC+Met & 6 & $459.9 \pm 6.0$ & $434.1 \pm 2.6^{\mathrm{a}}$ \\
rAAV9-Adrb1+Met & 6 & $459.0 \pm 3.0$ & $437.2 \pm 2.3^{\mathrm{a}}$ \\
\hline
\end{tabular}

${ }^{\mathrm{a}} \mathrm{P}<0.001$ vs. each group prior to Met intervention. Met, metoprolol; SHR, spontaneously hypertensive rats; $\beta 1$-AR, $\beta 1$-adrenergic receptor; rAAV9, recombinant adeno-associated virus type 9 vector; $\mathrm{NC}$, negative control; Adrb1, adrenergic receptor $\beta 1$; bmp, beats per minute.

Table II. Effect of cardiac $\beta 1$-AR suppression on heart rate in SHR.

\begin{tabular}{|c|c|c|c|}
\hline Groups & $\begin{array}{c}\text { No. of } \\
\text { samples }\end{array}$ & $\begin{array}{c}\text { Heart rate } \\
\text { prior to } \\
\beta 1-\mathrm{AR} \\
\text { suppression } \\
\text { (bmp) }\end{array}$ & $\begin{array}{c}\text { Heart rate } \\
\text { following } \\
\beta 1-\mathrm{AR} \\
\text { suppression } \\
\text { (bmp) }\end{array}$ \\
\hline Sham+saline & 4 & $461.7 \pm 3.7$ & $460.4 \pm 3.3$ \\
\hline rAAV9-NC & 5 & $459.9 \pm 6.0$ & $455.1 \pm 2.6$ \\
\hline rAAV9-Adrb1 & 6 & $459.0 \pm 3.0$ & $456.5 \pm 2.3$ \\
\hline
\end{tabular}

$\beta 1$-AR, $\beta 1$-adrenergic receptor; SHR, spontaneously hypertensive rats; rAAV9, recombinant adeno-associated virus type 9 vector; $\mathrm{NC}$, negative control; Adrb1, adrenergic receptor $\beta 1$; bmp, beats per minute.

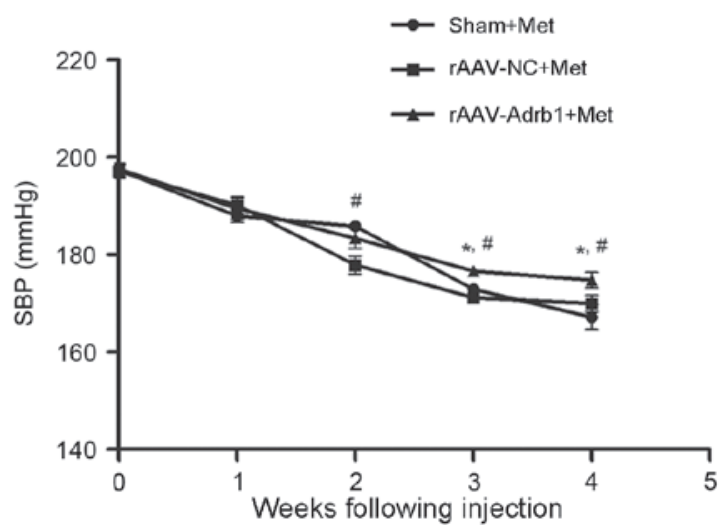

Figure 4. Effect of cardiac $\beta 1-A R$ downregulation on the SBP in SHR from sham, rAAV9-NC and rAAV9-Adrb1 groups up to 4 weeks following injection with saline, rAAV9-NC-ZsGreen and rAAV9-shRNA-Adrb1-ZsGreen vectors, respectively, and treatment with Met. ${ }^{*} \mathrm{P}<0.05$ vs. rAAV9-NC+Met group; ${ }^{\text {}} \mathrm{P}<0.05$ vs. the sham+Met group. $\beta 1$ - $\mathrm{AR}, \beta 1$-adrenergic receptor; SBP, systolic blood pressure; rAAV9, recombinant adeno-associated virus type 9 vector; NC, negative control; Adrb1, adrenergic receptor $\beta 1$; shRNA, short-hairpin RNA; Met, metoprolol.

gene knockout technology, the $24 \mathrm{~h}$ mean artery pressure was decreased by $10 \%(102.02 \pm 1.81$ vs. $92.11 \pm 2.62 \mathrm{mmHg})$

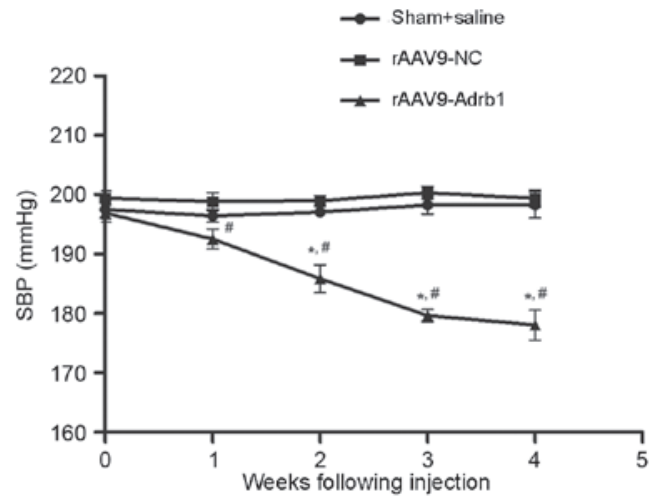

Figure 5. Effect of cardiac $\beta 1-A R$ downregulation on the SBP in SHR from sham+saline, rAAV9-NC and rAAV9-Adrb1 groups up to 4 weeks following injection with saline, rAAV9-NC-ZsGreen and rAAV9-shRNA-Adrb1-ZsGreen vectors, respectively. " $\mathrm{P}<0.05$ vs. rAAV9-NC group; ${ }^{\#} \mathrm{P}<0.05$ vs. sham+saline group. $\beta 1$-AR, $\beta 1$-adrenergic receptor; $\mathrm{SBP}$, systolic blood pressure; SHR, spontaneously hypertensive rats; rAAV9, recombinant adeno-associated virus type 9 vector; $\mathrm{NC}$, negative control; Adrb1, adrenergic receptor $\beta 1$; shRNA, short-hairpin RNA.

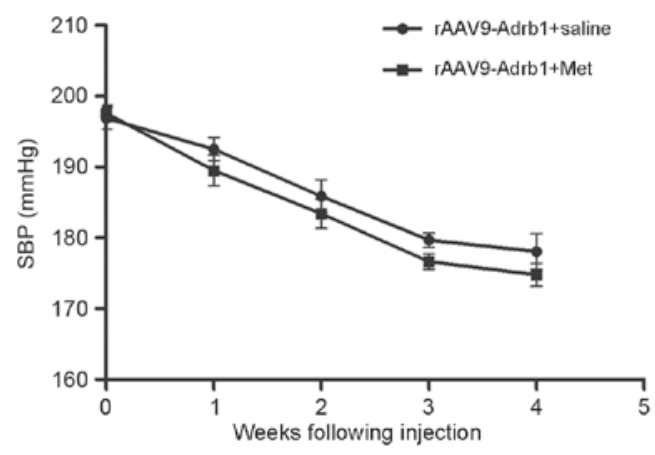

Figure 6. Effect of cardiac $\beta 1$-AR gene knockdown on SBP in SHR from the rAAV9-Adrb1 group up to 4 weeks following injection with the rAAV9-shRNA-Adrb1-ZsGreen vector and following saline or Met treatment. $\beta 1$-AR, $\beta 1$-adrenergic receptor; SBP, systolic blood pressure; SHR, spontaneously hypertensive rats; rAAV9, recombinant adeno-associated virus type 9 vector; Adrb1, adrenergic receptor $\beta 1$; shRNA, short-hairpin RNA; Met, metoprolol.

in $\beta 1 / \beta 2-A R^{-} /$compared with wild-type mice (31). Consistent with these results, a decrease in cardiac $\beta 1$-AR expression was associated with a reduction in SBP in the present study.

Since $\beta 1-A R$ is a member of the autonomic nervous system, the effect of cardiac $\beta 1$-AR expression on blood pressure regulation may be comprehensible. The $\beta 1$-AR subtype is often classified as the 'cardiac' $\beta$-AR subtype, due to the observation that the in vivo stimulation of this receptor by its agonists increases heart rate and contractility. It is known that stimulation of $\beta 1-A R$ induces robust chronotropic and inotropic effects via the Gs-protein adenylate cyclase-cyclic adenosine monophosphate-protein kinase A signaling pathway (32). Following stimulation of $\beta 1-\mathrm{AR}$, protein kinase $\mathrm{A}$ is activated and L-type $\mathrm{Ca}^{2+}$ channels in ventricular myocytes are phosphorylated, which leads to increased myocardial contractility through increased $\mathrm{Ca}^{2+}$ influx and the release of $\mathrm{Ca}^{2+}$ from the sarcoplasmic reticulum. Zhang et al (30) observed a marked attenuation of the $\beta 1-A R$-mediated positive inotropic response in isolated perfused hearts in vitro and in conscious SHR 
following myocardial $\beta 1-A R$ downregulation. Through the targeted deletion of $\beta 1-\mathrm{AR}$, mice lacking $\beta 1-\mathrm{AR}$ were demonstrated to exhibit increased heart rate variability and decreased resting heart rate (33). Therefore, myocardial $\beta 1$-AR expression may influence blood pressure regulation by affecting heart rate and cardiac output through altering cardiac inotropy and chronotropy.

In the present study, decreasing $\beta 1$-AR expression in the myocardium decreased blood pressure but had no significant effect on heart rate in SHR. Which is consistent with several previous studies (29-30). It is therefore possible that $\beta 2$-AR may serve a more important role in regulating heart rate compared with $\beta 1-A R$ (29). However, a previous study revealed that $\beta 1$-AR may also function to control heart rate (33). Ecker et al (33) demonstrated that resting heart rate (in beats/min) was decreased in $\beta 1$-knockout $(\mathrm{KO})$ and $\beta 1 / \beta 2$-double KO mice when compared with wild-type mice. The possible reasons underlying these contradictory results require further investigation in future studies.

The present study was limited by the small sample size and $\beta 1-A R$ was downregulated only in the myocardium by injection of lentiviral shRNA vectors directly into the pericardial cavity (34). The results demonstrated that $\beta 1$-AR expression in the myocardium affects the efficacy of Met in SHR. In addition, cardiac $\beta 1-\mathrm{AR}$ expression may be associated with blood pressure regulation, however, the effect of $\beta 1$-AR expression on cardiac physiology was not investigated in the present study. Therefore, the clinical applications or mechanisms involved in B1-AR-mediated regulation of blood pressure and response to Met treatment warrant attention in future studies. The rAAV9 vector, used to deliver shRNA to the myocardium in vivo in the present study, is a valuable, safe and efficacious means of cardiac gene transfer (18). However, its potential effects on cardiac function and the immune system were not examined. This will be an important aim in future studies.

\section{Acknowledgements}

The present study was supported by grants from The National Natural Science Foundation of China (grant no. 81470535), The National Science and Technology Major Projects for 'Major New Drugs Innovation and Development' (grant no. 2012ZX09303014001) and The National Key Technology Research and Development Program (grant no. 2012BAI137B05).

\section{References}

1. Chen S: Essential hypertension: Perspectives and future directions. J Hypertens 30: 42-45, 2012.

2. Chinese National Center for Cardiovascular Diseases (CNCCD): Report on Cardiovascular Diseases in China 2013.

3. Sheng CS, Liu M, Kang YY, Wei FF, Zhang L, Li GL, Dong Q, Huang QF, Li Y and Wang JG: Prevalence, awareness, treatment and control of hypertension in elderly Chinese. Hypertens Res 36: 824-828, 2013.

4. Lim SS, Vos T,Flaxman AD, Danaei G, Shibuya K, Adair-RohaniH, Amann M, Anderson HR, Andrews KG, Aryee M, et al: A comparative risk assessment of burden of disease and injury attributable to 67 risk factors and risk factor clusters in 21 regions, 1990-2010: A systematic analysis for the Global Burden of Disease Study 2010. Lancet 380: 2224-2260, 2012.

5. Tibazarwa KB and Damasceno AA: Hypertension in developing countries. Can J Cardiol 30: 527-533, 2014.
6. Yancy CW,Jessup M,Bozkurt B,Butler J,Casey DE Jr,DraznerMH, Fonarow GC, Geraci SA, Horwich T, Januzzi JL, et al: 2013 ACCF/AHA guideline for the management of heart failure: A report of the American College of Cardiology Foundation/American Heart Association Task Force on Practice Guidelines. J Am Coll Cardiol 62: e147-e239, 2013

7. McAlister FA, Wiebe N, Ezekowitz JA, Leung AA and Armstrong PW: Meta-analysis: Beta-blocker dose, heart rate reduction, and death in patients with heart failure. Ann Intern Med 150: 784-794, 2009.

8. Materson BJ, Reda DJ, Cushman WC, Massie BM, Freis ED, Kochar MS, Hamburger RJ, Fye C, Lakshman R and Gottdiener J: Single-drug therapy for hypertension in men. A comparison of six antihypertensive agents with placebo. The Department of Veterans Affairs Cooperative Study Group on Antihypertensive Agents. N Engl J Med 328: 914-921, 1993.

9. Johnson JA and Liggett SB: Cardiovascular pharmacogenomics of adrenergic receptor signaling: Clinical implications and future directions. Clin Pharmacol Ther 89: 366-378, 2011.

10. Bijl MJ, Visser LE, van Schaik RH, Kors JA, Witteman JC, Hofman A, Vulto AG, van Gelder T and Stricker BH: Genetic variation in the CYP2D6 gene is associated with a lower heart rate and blood pressure in beta-blocker users. Clin Pharmacol Ther 85: 45-50, 2009.

11. Zhou SF: Polymorphism of human cytochrome P450 2D6 and its clinical significance: Part II. Clin Pharmacokinet 48: 761-804, 2009.

12. Wu D, Li G, Deng M, Song W, Huang X, Guo X, Wu Z, Wu S and $\mathrm{Xu}$ J: Associations between ADRB1 and CYP2D6 gene polymorphisms and the response to $\beta$-blocker therapy in hypertension. J Int Med Res 43: 424-434, 2015.

13. Yuan H, Huang Z, Yang G, Lv H, Sang H and Yao Y: Effects of polymorphism of the beta(1) adrenoreceptor and CYP2D6 on the therapeutic effects of metoprolol. J Int Med Res 36: 1354-1362, 2008.

14. Rockman HA, Koch WJ and Lefkowitz RJ: Seven- transmembrane-spanningreceptors and heart function. Nature 415: 206-212, 2002

15. Jiang Q, Yuan H, Xing X, Liu J, Huang Z and Du X: Methylation of adrenergic $\beta 1$ receptor is a potential epigenetic mechanism controlling antihypertensive response to metoprolol. Indian J Biochem Biophys 48: 301-307, 2011.

16. Liu H, Xing X, Huang L, Huang Z and Yuan H: The expression level of myocardial $\beta 1$-adrenergic receptor affects metoprolol antihypertensive effects: A novel mechanism for interindividual difference. Med Hypotheses 81: 71-72, 2013.

17. Vandenberghe LH, Xiao R, Lock M, Lin J, Korn M and Wilson JM: Efficient serotype-dependent release of functional vector into the culture medium during adeno-associated virus manufacturing. Hum Gene Ther 21: 1251-1257, 2010.

18. Mueller C, Ratner D, Zhong L, Esteves-Sena M and Gao G: Production and discovery of novel recombinant adeno-associated viral vectors. Curr Protoc Microbiol Chapter 14:Unit14D.1, 2012.

19. Wu XB, Dong XY, Wu ZJ, Cao H, Niu DB, Qu JG, Wang H and Hou YD: A novel method for purification of recombinant adenoassociated virus vectors on a large scale. Chinese Sci Bull 46: pp485-488, 2001.

20. McClure C, Cole KL, Wulff P, Klugmann M and Murray AJ: Production and titering of recombinant adeno-associated viral vectors. J Vis Exp e3348, 2011.

21. Bish LT, Sweeney HL, Müller OJ and Bekeredjian R: Adeno-associated virus vector delivery to the heart. Methods Mol Biol 807: 219-237, 2011.

22. Katz MG, Swain JD, Tomasulo CE, Sumaroka M, Fargnoli A and Bridges CR: Current strategies for myocardial gene delivery. J Mol Cell Cardiol 50: 766-776, 2011.

23. Livak KJ and Schmittgen TD: Analysis of relative gene expression data using real-time quantitative PCR and the 2(Delta Delta C(T)) method. Methods 25: 402-408, 2001.

24. Naya M, Tsukamoto T, Morita K, Katoh C, Nishijima K, Komatsu H, Yamada S, Kuge Y, Tamaki N and Tsutsui H: Myocardial beta-adrenergic receptor density assessed by 11C-CGP12177 PET predicts improvement of cardiac function after carvedilol treatment in patients with idiopathic dilated cardiomyopathy. J Nucl Med 50: 220-225, 2009.

25. Ferrara N, Komici K, Corbi G, Pagano G, Furgi G, Rengo C, Femminella GD, Leosco D and Bonaduce D: $\beta$-adrenergic receptor responsiveness in aging heart and clinical implications. Front Physiol 4: 396, 2014.

26. Hellgren I, Sylven C and Magnusson Y: Study of the beta1 adrenergic receptor expression in human tissues: Immunological approach. Biol Pharm Bull 23: 700-703, 2000. 
27. Oliver E, Rovira E, Montó F, Valldecabres C, Julve R, Muedra V, Ruiz N, Barettino D and D'Ocon P: beta-Adrenoceptor and GRK3 expression in human lymphocytes is related to blood pressure and urinary albumin excretion. J Hypertens 28: 1281-1289, 2010.

28. Hamdani $\mathrm{N}$ and Linke WA: Alteration of the beta-adrenergic signaling pathway in human heart failure. Curr Pharm Biotechnol 13: 2522-2531, 2012.

29. Arnold AS, Tang YL, Qian K, Shen L, Valencia V, Phillips MI and Zhang YC: Specific betal-adrenergic receptor silencing with small interfering RNA lowers high blood pressure and improves cardiac function in myocardial ischemia. J Hypertens 25: 197-205, 2007.

30. Zhang YC, Bui JD, Shen L and Phillips MI: Antisense inhibition of beta(1)-adrenergic receptor mRNA in a single dose produces a profound and prolonged reduction in high blood pressure in spontaneously hypertensive rats. Circulation 101: $682-688,2000$
31. Kim SM, Huang Y, Qin Y, Mizel D, Schnermann J and Briggs JP: Persistence of circadian variation in arterial blood pressure in beta1/beta2-adrenergic receptor-deficient mice. Am J Physiol Regul Integr Comp Physiol 294: R1427-R1434, 2008.

32. Yoo B, Lemaire A, Mangmool S, Wolf MJ, Curcio A, Mao L and Rockman HA: Beta1-adrenergic receptors stimulate cardiac contractility and CaMKII activation in vivo and enhance cardiac dysfunction following myocardial infarction. Am J Physiol Heart Circ Physio 1297: H1377-H1386, 2009.

33. Ecker PM, Lin CC, Powers J, Kobilka BK, Dubin AM and Bernstein D: Effect of targeted deletions of beta1andbeta2-adrenergic-receptor subtypes on heart rate variability. Am J Physiol Heart Circ Physiol 290: H192-H199, 2006.

34. Chen SJ, Johnston J, Sandhu A, Bish LT, Hovhannisyan R, Jno-Charles O, Sweeney HL and Wilson JM: Enhancing the utility of adeno-associated virus gene transfer through inducible tissue-specific expression. Hum Gene Ther Methods 24: 270-278, 2013 